\title{
NASA Proof-of-Concept 1-W Stirling Convertor Development for Small RPS
}

\author{
Nicholas A. Schifer ${ }^{1}$, Scott D. Wilson ${ }^{2}$, Daniel D. Goodell ${ }^{3}$ \\ NASA Glenn Research Center, Cleveland, $\mathrm{OH} 44135$
}

\author{
Michael R. Casciani ${ }^{4}$ \\ Vantage Partners, LLC., Brook Park, OH 44142
}

\begin{abstract}
Low power Stirling convertors are being developed at NASA Glenn Research Center (GRC) to provide future small spacecraft with electrical power by converting heat from one or more Light Weight Radioisotope Heater Units (LWRHU). An initial design converts multiple watts of heat to one watt of electrical power output using a Stirling convertor. A variety of mission concepts have been studied by NASA and the U. S. Department of Energy (DOE) that would utilize low power Radioisotope Power Systems (RPS) for probes, landers, rovers, and repeaters. These missions would contain science instruments distributed across planetary surfaces or near objects of interest where solar flux is insufficient for using solar cells. Landers could be used to provide data such as, radiation, temperature, pressure, seismic activity, and other surface measurements for planetary science and to inform future mission planners. The studies propose using fractional versions of the General Purpose Heat Source (GPHS) or multiple LWRHUs to heat power conversion technologies for science instruments and communication. Dynamic power systems are capable of higher conversion efficiencies, which could enable equal power using less fuel or more power using equal fuel, when compared to less efficient static power conversion technologies. Providing spacecraft with more power would decrease duty cycling of basic functions and, therefore, increase the quality and abundance of science data. Efforts to develop the concept have focused on maturation of a 1-We convertor and controller design and performance evaluation of an evacuated metal foil insulation. A proof-of-concept 1-We convertor, controller, and evacuated metal foil insulation package have been fabricated and are undergoing characterization testing. The current status, findings, and path forward for the effort are explained in this paper.
\end{abstract}

\section{Nomenclature}

$\begin{array}{ll}\text { DOE } & =\text { Department of Energy } \\ G R C & =\text { Glenn Research Center } \\ G P H S & =\text { General Purpose Heat Source } \\ \text { LWRHU } & =\text { Light Weight Radioisotope Heater Units } \\ M L M I & =\text { Multi-Layer Metal Insulation } \\ R P S & =\text { Radioisotope Power System } \\ T E & =\text { Thermoelectric }\end{array}$

\footnotetext{
${ }^{1}$ Mechanical Engineer, Thermal Energy Conversion Branch, 21000 Brookpark Rd, AIAA Non-Member.

${ }_{2}^{2}$ Mechanical Engineer, Thermal Energy Conversion Branch, 21000 Brookpark Rd, AIAA Non-Member.

${ }^{3}$ Mechanical Engineer, Thermal Energy Conversion Branch, 21000 Brookpark Rd, AIAA Non-Member.

${ }^{4}$ Electrical Engineer, Vantage Partners, LLC., 3000 Aerospace Parkway, Brook Park OH, AIAA Non-Member.
} 


\section{The Push for Small Radioisotope Power Systems}

A NASA/DOE survey identified many scientifically valuable mission concepts and applications that could benefit from small-RPS flight systems. The mission studies considered Thermoelectric (TE) and Stirling cycle-based conversion technologies. Of the 51 missions studied by the Jet Propulsion Laboratory, Goddard Space Flight Center, and Ames Research Center, 13 of the missions used low power systems that produced $3 \mathrm{~W}$ to $9 \mathrm{~W}$ electrical power from fractional versions of the General Purpose Heat Source (GPHS), and 14 of the missions used low power systems that produced $5 \mathrm{~mW}$ to $500 \mathrm{~mW}$ of electrical power from one or more Light Weight Radioisotope Heater Units (LWRHU) as a heat source (Ref. [1]). These small RPS systems could extend the capability of small science payloads and instruments to enable meteorological and seismological stations distributed across planetary surfaces, small landers in regions of low solar flux, subsurface probes, surface and atmosphere-based mobility systems, and deep space micro-spacecraft. Batteries and super-capacitors were required for most designs to enable periodic power intensive functions like data collection, communications, and roving. These studies assumed a static TE based system with 5\% conversion efficiency and concluded that power requirement increased as the capability of each mission increased. Stirling cycle-based conversion could improve system efficiency by 3-4 times, increasing mission capability and science data return for low power applications.

An in-house team was assembled at NASA Glenn Research Center (GRC) to assess the feasibility of high efficiency dynamic convertors at much lower power levels, suitable for use with LWRHUs. Initial efforts have led to a design to convert 1 watt of useable direct current electric power for the spacecraft instrumentation and communication (Ref. [2]).

\section{System Architecture and Design}

A systems approach was taken in the development of a 1-We Stirling convertor where all system interfaces were considered early in the design, and proof-of-concept designs were developed for each of the major components. Maturation of the major subassemblies that make up the small RPS include a heat source assembly, free-piston Stirling convertor, electrical controller, and insulation package and associated structure. The design effort has focused on minimization of thermal and electrical losses for the insulation, convertor, and controller while providing a notional heat source assembly design that will require further maturation. Fig. 1 shows the concept with integrated convertor and heater assembly inside the insulation package. This RPS concept has a mass of under $3 \mathrm{~kg}$ and is roughly $32 \mathrm{~cm}$ long and $11 \mathrm{~cm}$ in diameter. The heat source is mounted inside the insulation package and is radially constrained using point contacts to minimize internal thermal losses. The heat source and Stirling hot end are radiatively coupled using closely spaced non-contacting plates. The Stirling convertor is constrained at the cold end and the heater head is radially constrained using point contacts. This design would avoid mechanical loading of the thin-walled Stirling heater head while still enabling an adequate Stirling hot-end temperature. The concept keeps the controller warm by encapsulating it inside the housing near the rejection flange, which will offer approximately 4 watts of waste heat.

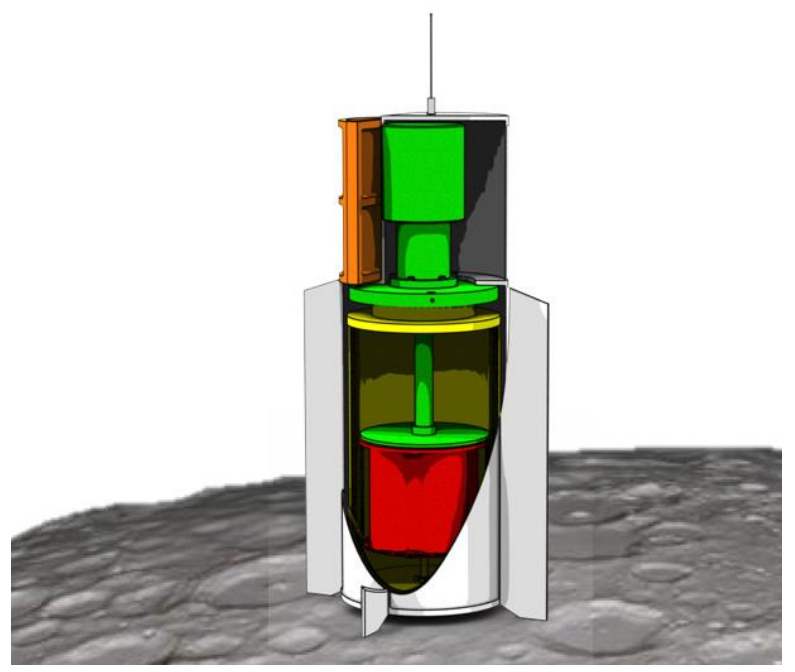

Fig. 1 Conceptualization of the small dynamic RPS on the lunar surface. 


\section{Insulation Package}

A proof-of-concept multi-layer metal insulation (MLMI) was designed and fabricated by Peregrine Falcon Corporation under contract with GRC. With such little heat available from the LWRHU, a highly effective insulation package is needed to provide the engine with the heat needed to drive the thermodynamic cycle. Fig. 2 shows an image of the MLMI with an electric heat source, a Stirling thermal simulator, and fluid heat rejection loop. The figure also shows the delivered configuration that utilizes a large Conflat flange to enable high vacuum levels and disassembly and inspection of the thermal simulator between tests. The proof-of-concept package was designed to simulate the critical heat pathways for the system concept described above. An electrically-heated LWRHU simulator utilizes four vacuum rated cartridge heaters to simulate the 8 watts thermal input anticipated from eight LWRHUs configured in groupings of four and stacked two high. The heat source is radiatively coupled to a heat collector on the thermal simulator. The thermal simulator contains an insertion rod that is instrumented with thermocouples to enable calculation of heat transfer through the assembly. Such data will be used to validate thermal models and verify the performance of the insulation package. A fluid heat exchanger is included to remove heat at the cold end of the assembly. The MLMI package utilizes strategically located thin metallic shields to minimize conduction heat loss to the environment. The design is evacuated to eliminate convection heat transfer and minimize parasitic conduction losses at internal interfaces. This assembly is adequate for testing in air or vacuum to simulate potential mission environments. This same package was also designed for reconfiguration to enable testing with the proof-of-concept $1 \mathrm{~W}_{\mathrm{e}}$ convertor instead of the thermal simulator. Testing of this hardware is underway at GRC and another paper has been written and is being presented at IECEC 2019 on the topic of the insulation package, which will give detail on the design and testing of this hardware.

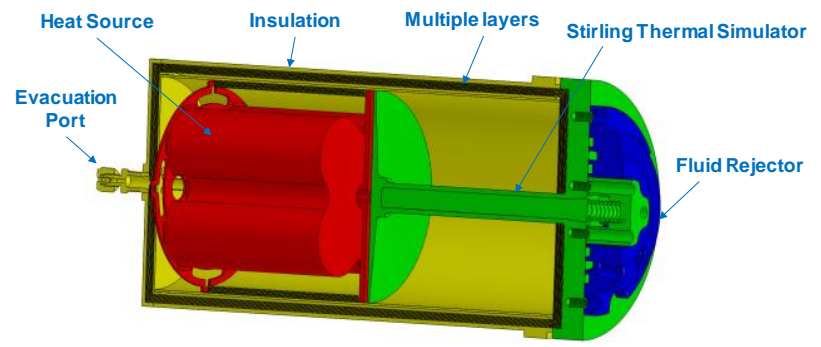

Fig. 2 Proof-of-concept insulation package.

\section{1-Watt Convertor}

A proof-of-concept Stirling convertor has been designed for easy assembly in a laboratory environment and has been prepared to support initial testing. A split-Stirling configuration was selected for ease of assembly and component testing from among a field of options and utilizes a gap regenerator, which is basically a two-walled foil regenerator and does not contain any engineered microstructures. Table I shows the engine and alternator design parameters, including a mean charge pressure of 94 PSIG and hot-end temperature of $350{ }^{\circ} \mathrm{C}$, both of which are considered to be relatively low compared to higher power designs for space. The hot-end temperature was selected to minimize insulation losses and heat source surface temperature. The Stirling cycle was designed for an operating frequency of 100 $\mathrm{Hz}$ and displacer and piston amplitudes of $2 \mathrm{~mm}$ and $4 \mathrm{~mm}$, respectively. The convertor utilizes an alternator with a solid core material and button style magnet, making the design simple to assemble and robust to overstroke events. The alternator also used flexure bearings to maintain the radial running clearances that are required for long life wear-free operation.

\section{Table I Stirling Convertor Design} Parameters

\begin{tabular}{|c|c|}
\hline Parameter & Goal \\
\hline Electrical output, $\mathrm{W}_{\mathrm{e}}$ & 1.0 \\
\hline Thermal input, $\mathrm{W}_{\mathrm{th}}$ & 6.5 \\
\hline Convertor efficiency, $\%$ & 20 \\
\hline Alternator efficiency, $\%$ & 85 \\
\hline Acceptor temperature, ${ }^{\circ} \mathrm{C}$ & 350 \\
\hline Rejector temperature, ${ }^{\circ} \mathrm{C}$ & $<50$ \\
\hline Operating frequency, $\mathrm{Hz}$ & 100 \\
\hline Mean pressure, PSIG & 94 \\
\hline Pressure amplitude, PSI & 13 \\
\hline Displacer amplitude, $\mathrm{mm}$ & 2.0 \\
\hline Piston amplitude, $\mathrm{mm}$ & 4.0 \\
\hline
\end{tabular}

Fig. 3 shows the prototype design used to perform a proof of concept of the very low power machine. This version does not emphasize small size or low mass but does enable a wide variety of instrumentation for parameter measurement and bolted flanges for ease of disassembly and inspection. These features would not be present in flight designs. A thick-wall gas duct was used in place of a small diameter gas line to enable testing of two different 
alternator designs with bolted configurations. Fig. 4 shows a section view of the convertor with callouts of instrumentation locations and key components. Internal position sensors were included for the displacer and piston position, which enable measurement of the amplitudes and the phase angle between the moving components and alternator current. A pressure transducer was also included for measurement of the compression-space dynamic pressure amplitude. Thermocouples were installed on the hot end, cold end, and alternator housing for measurement of key temperatures. These measurements enable characterization of the thermodynamically-dynamically coupled machine. Future versions will minimize mass, size, and sensors.

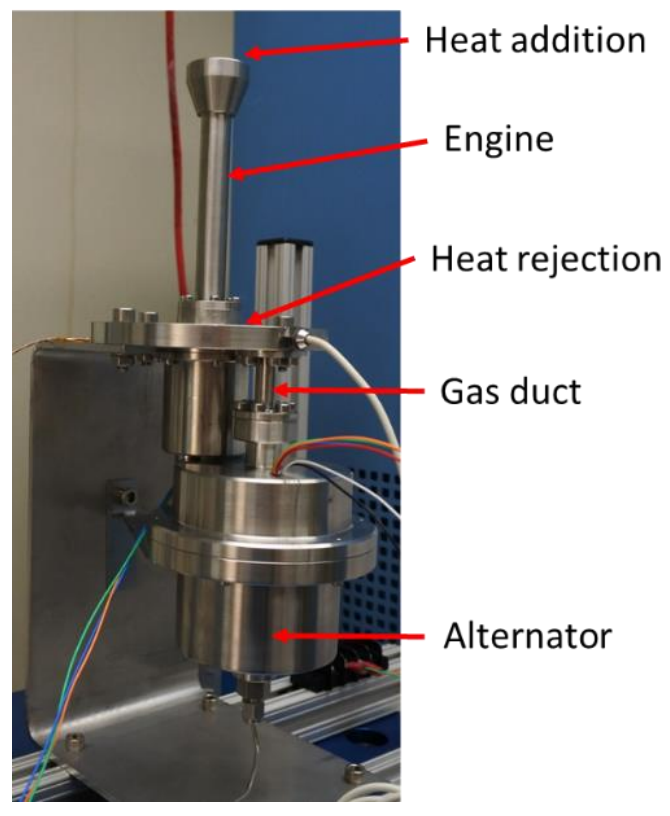

Fig. 3 Stirling convertor test setup.

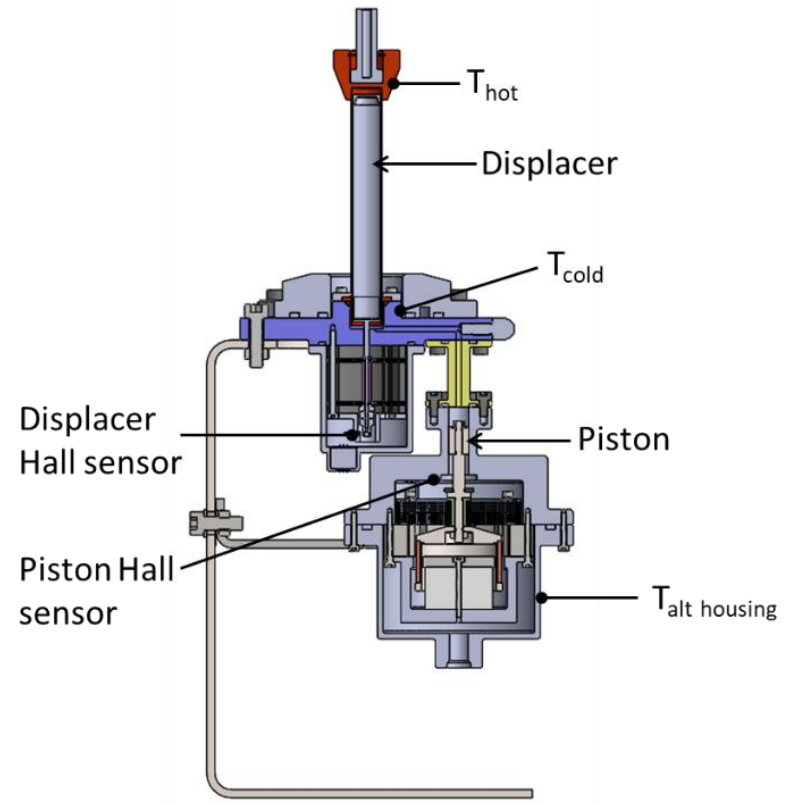

Fig. 4 Section view of the convertor with callouts of instrumentation locations and key components.

Testing of this hardware at GRC is underway, and discussion of the test results will be summarized in this paper. Completed activities include a proof pressure test of the pressure boundaries, stiffness characterization of the flexures, installation and alignment of the piston and displacer within the close clearance bores, rough tuning of piston and displacer resonances, piston and displacer position sensor calibration, convertor charging with helium, and initial motoring operation of the assembled convertor.

\section{A. Flexure Stiffness Characterization}

A force versus displacement characterization of the piston and displacer flexures was completed to characterize the stiffness of the flexures relative to amplitude. One assembly consisting of two piston flexures and a second assembly consisting of four displacer flexures were used for these tests. These assemblies utilized as much convertor hardware as possible to properly represent the same mounting interfaces as the flexures would experience when installed in the convertor. A calibrated mass set was used to apply a known force to the center of the each flexure assembly and a laser sensor was used to measure displacement. Mass was incrementally added and test points collected until each flexure assembly was deflected through their full design amplitudes. Each empirical test was performed twice for repeatability and compared against finite element modeling results. Fig. 5 and Fig. 6 show the results for the displacer and piston flexures, respectively, in comparison to the model results. Generally, at low amplitudes the model and test results are in agreement, but as deflection amplitude increased, the model increasingly over predicted flexure stiffness. At the respective displacer and piston nominal amplitudes of 2 and $4 \mathrm{~mm}$, the finite element model over predicted flexure stiffness by $7 \%$ and $13 \%$. 


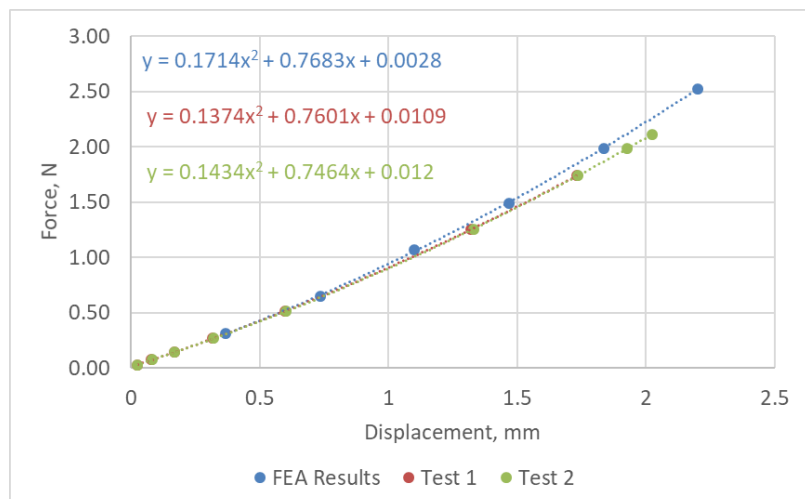

Fig. 5 Displacer flexure force versus displacement curves.

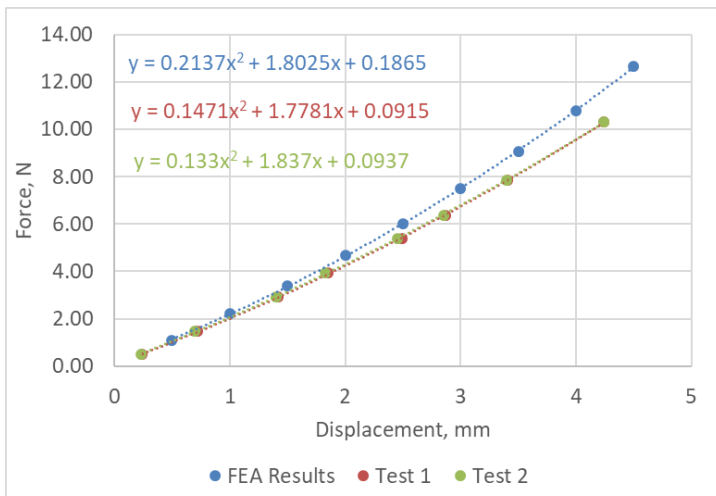

Fig. 6 Piston flexure force versus displacement curves.

\section{B. Displacer and Piston Resonance Characterization}

The piston and displacer assemblies were first tuned as two independent one degree of freedom systems. The basic rule of thumb for Stirling design is that displacer resonance must be greater than the piston resonance for stable operation, and that the convertor operating frequency will fall somewhere between resonances of the two systems. With a desired convertor frequency of $100 \mathrm{~Hz}$, the goal of this tuning effort was to achieve displacer resonance slightly above $100 \mathrm{~Hz}$ and piston resonance slightly below $100 \mathrm{~Hz}$.

The approach taken to characterize displacer resonance was to mount the displacer assembly onto the same frame as the alternator, such that the two were mechanically coupled only through the frame. Fig. 7 shows the test setup used for characterizing displacer resonance. A laser displacement sensor was aimed at the displacer to measure displacer motion, and the $1 \mathrm{We}$ linear alternator was motored via an AC source at low amplitude and a frequency that was below the estimated resonant frequency of the displacer system. The vibration from the linear alternator transmitted through the structure resulting in base excitation of the displacer assembly. Frequency was increased and displacer motion monitored. Due to the stiffness of the displacer flexures being non-constant, the resonant frequency of the system grows with amplitude. For this reason, the approach taken was to adjust the stiffness of the displacer assembly by adding or removing flexures until the displacer resonated at the design amplitude of $2 \mathrm{~mm}$ at a frequency slightly above $100 \mathrm{~Hz}$. Adjustments were made such that a $2 \mathrm{~mm}$ amplitude was achieved at frequency of $\sim 103 \mathrm{~Hz}$. Fig. 8 shows the resulting displacer amplitude versus frequency curve that was developed during this characterization. This approach to characterizing displacer resonance also verified that the displacer was properly aligned and free of rubs throughout the entire range of motion, as a minor rub would have caused displacer motion to stop. The displacer was also observed to ringdown freely as displacer motion continued for more than one second after excitation from the alternator ceased. 

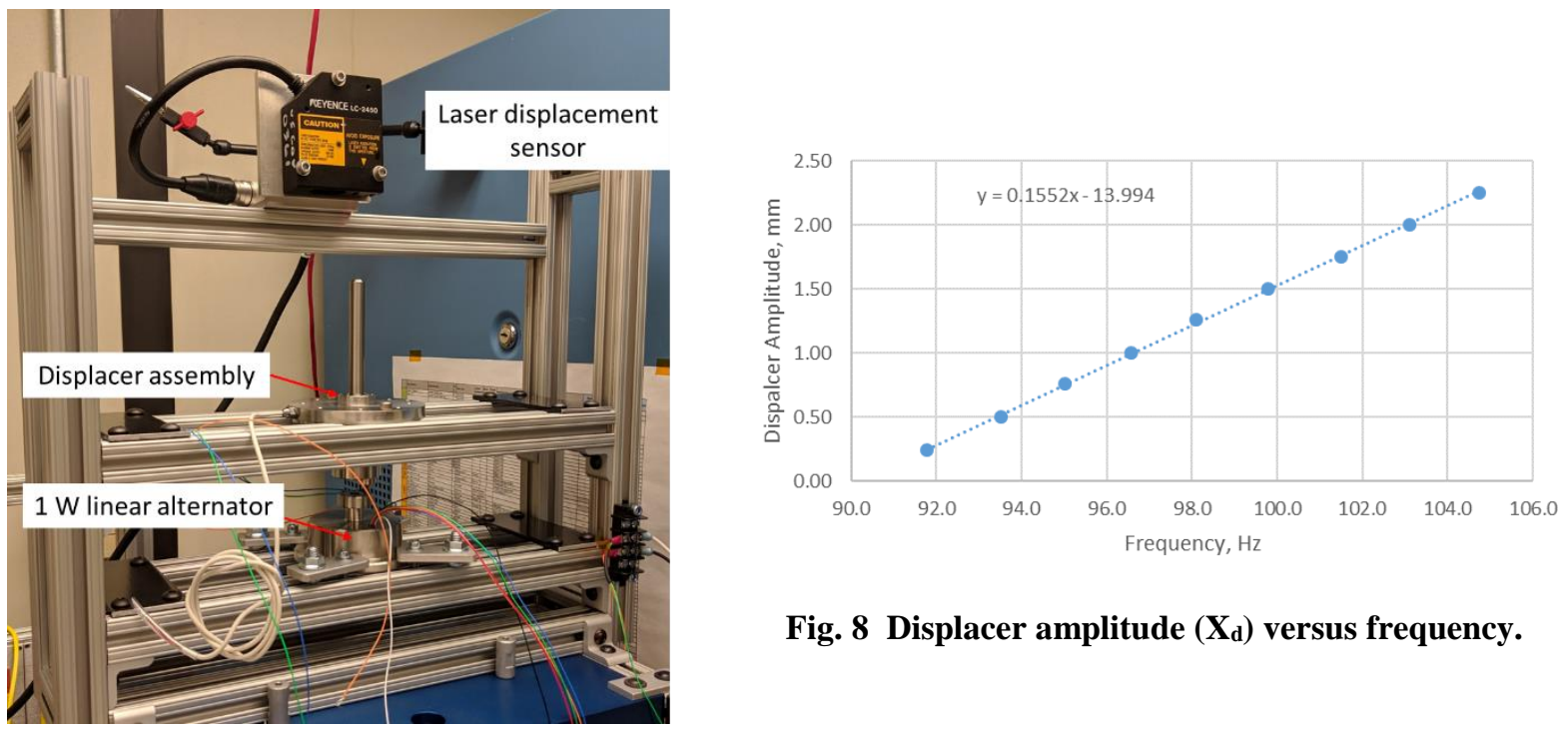

Fig. 8 Displacer amplitude $\left(\mathbf{X}_{\mathrm{d}}\right)$ versus frequency.

Fig. 7 Test setup used for characterizing displacer resonance.

The approach taken to characterize piston resonance was to drive the alternator via an AC source up to full design piston amplitude of $4 \mathrm{~mm}$ and then removed the load on the alternator to allow the resonant system to ringdown freely. A laser displacement sensor was pointed at the face of the piston to measure piston amplitude and monitored on an oscilloscope. Regardless of driving frequency, as soon as the load was removed from the alternator by switching to open circuit via relay, the piston resonant system began to oscillate at its natural frequency. Due to the stiffness of the piston flexures being non-constant, the natural frequency during amplitude decay of the piston was decreasing. For this reason, only the first couple of cycles during ring down were analyzed to determine the resonant frequency near the design amplitude of $4 \mathrm{~mm}$. Adjustments were made such that at $4 \mathrm{~mm}$ a piston resonant frequency of $\sim 95 \mathrm{~Hz}$ was achieved. This approach to characterizing piston also verified that the piston was properly aligned and free of rubs throughout the entire range of motion, as a minor rub would have caused rapid decay of motion during the ringdown process. A piston free of rubs should freely ring for more than one second.

\section{Piston and Displacer Position Sensor Calibration}

The ability to monitor accurately the relative motion of piston and displacer is necessary for debugging convertor operation and comparing to analysis results. Hall effect sensors were selected and paired with magnets attached to the moving components of the piston and displacer assemblies to serve as position sensors. Filtering was applied to both hall effect signals, and therefore the phase shift in the signals was characterized and must be considered when comparing relative phases of the piston, displacer, and dynamic pressure of the compression space. The filter phase shift was characterized using a waveform generator to simulate the hall sensor voltage and adjusting the frequency through the expected range of operating frequencies. The raw and filtered signals were then compared to determine the phase shift. An equation of phase shift as a function of frequency was developed for correcting the signals during post processing. Amplitude calibration of the piston and displacer hall sensors was completed using the same techniques as described for resonant frequency characterization to drive each component. A LabVIEW data acquisition system was used to collect the voltage amplitude of the hall sensor outputs and the calculated amplitude in millimeters from the laser displacement sensor. A relation of the hall sensor voltage amplitude to the measured laser amplitude was then developed to scale the hall sensor output to amplitude in millimeters. Fig. 9 shows that this relationship of hall sensor output voltage versus laser amplitude is linear for both the piston and displacer position sensors over their design amplitude ranges. Fig. 10 shows an example of the dynamic piston and displacer signals from the hall effect position sensors, and the cycle pressure waveform, all collected at a $7 \mathrm{kHz}$ sample rate using the LabVIEW data acquisition system. 

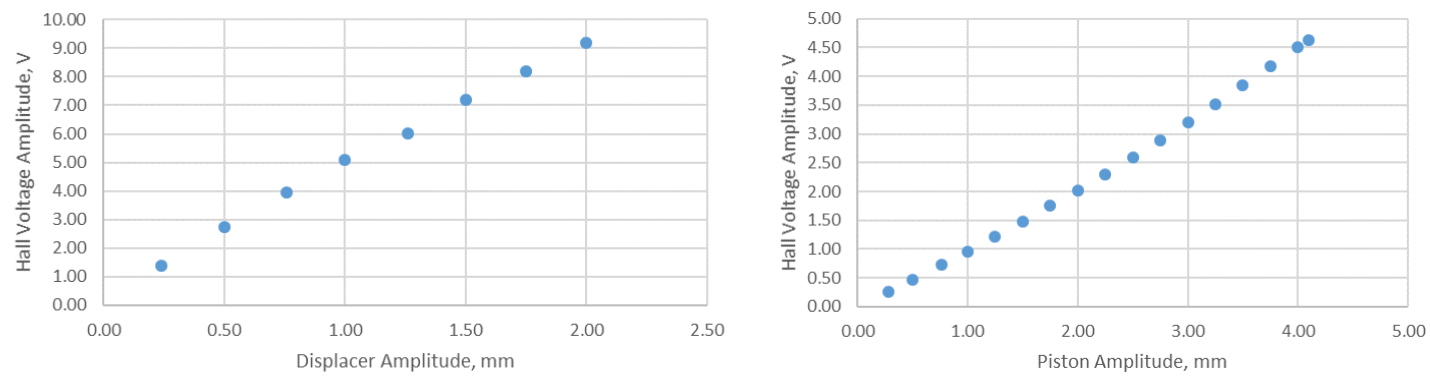

Fig. 9 Left: Displacer position sensor calibration data. Right: Piston position sensor calibration data.

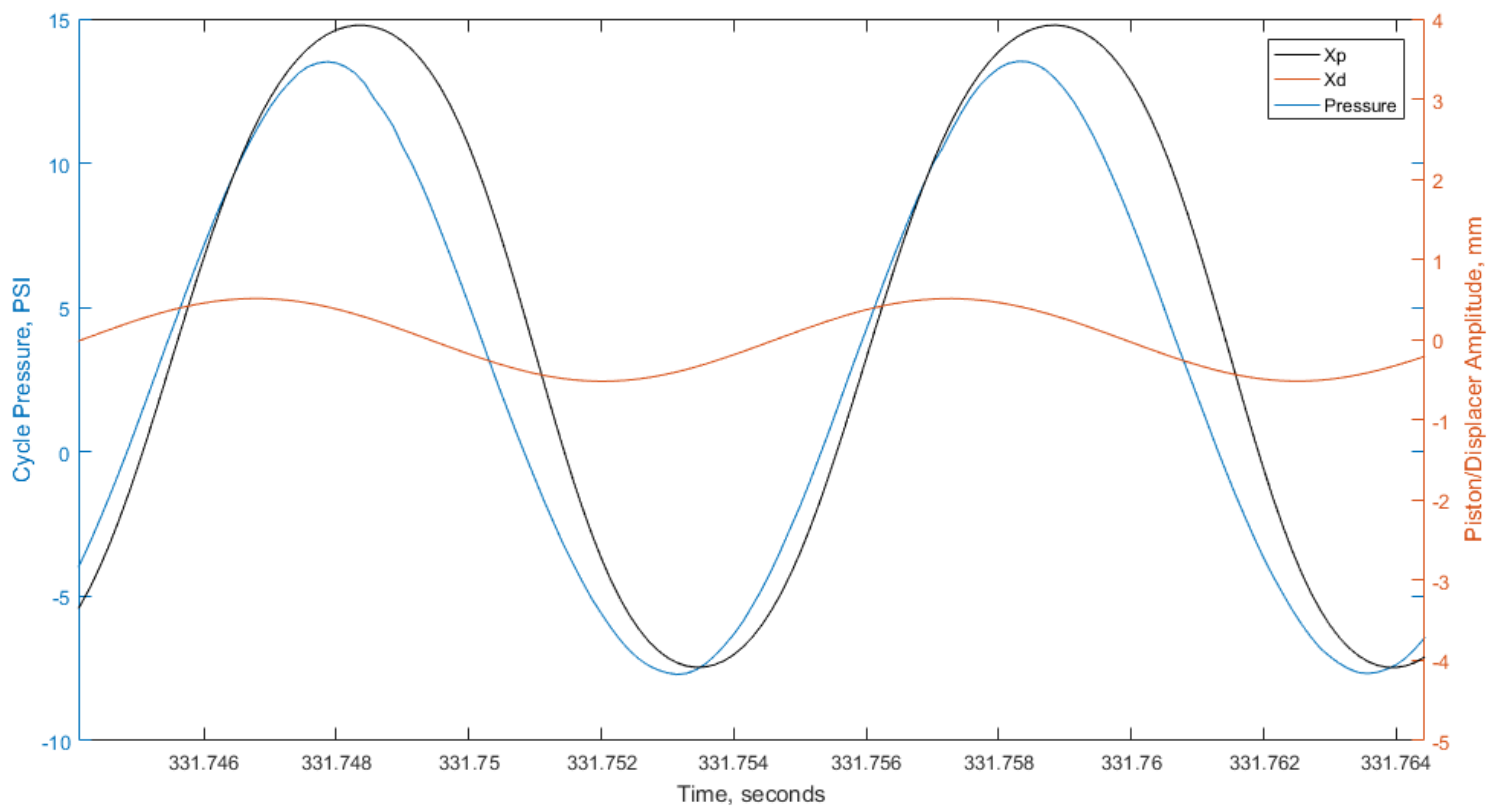

Fig. 10 Piston amplitude (Black), displacer amplitude (orange), and cycle pressure (blue).

\section{Convertor Characterization}

The engine and alternator assemblies were integrated and characterized as a system. A five times fill and purge procedure was completed to reduce the risk of oxygen contamination in the helium fill of the convertor. This process consisted of filling the convertor to 100 PSIG and depressurizing to 10 PSIG five times, followed by final fill to a charge pressure of 98 PSIG. The first characterization of the convertor consisted of motoring the convertor using an AC source to drive the piston amplitude to $2 \mathrm{~mm}$ at frequencies of $95-103 \mathrm{~Hz}$. During this test it was observed that the convertor operated in one of two modes generally defined by the piston-displacer phase angle. In the first mode, the displacer was leading the piston by $\sim 170$ degrees, and the convertor functioned as a heat pump, pumping heat to the hot-end of the convertor. In the second mode, the displacer and piston were nearly in phase, and the convertor functioned as a heat pump, pumping heat to the cold end of the convertor. This same test was repeated a second time, but with a piston amplitude of $4 \mathrm{~mm}$, and the same two operating modes were observed. In both of these tests it was observed that at each frequency there was a certain piston amplitude achieved at which the phasing of the piston and displacer changed from nearly in phase to nearly out of phase. It was also observed that as the frequency was increased, the piston amplitude required to induce the phase change increased. After the phase shift occurred, the displacer achieved higher amplitudes as frequency increased, which made sense given the non-constant displacer flexure stiffness. There were also cases at the higher frequencies where the phase shift was not observed. It was believed that this phenomenon was directly related to the stiffness of the displacer flexures being non-constant and to case motion of the cantilevered mount that was used. Fig. 3 shows the C-shaped mount that was used during this test. A laser was later used to measure the case motion of this non-rigid mounting structure to be on the order of $0.1 \mathrm{~mm}$ when the piston amplitude was $4 \mathrm{~mm}$. 
A second abbreviated characterization test was completed with the only difference being that the convertor was mounted more rigidly. Fig. 11 shows an extruded aluminum frame that was constructed to provide a more rigid convertor mounting structure. Fig. 12 and Fig. 13 show the piston-displacer phase angle and displacer amplitude versus frequency for the two tests with non-rigid and rigid mounting. Mounting greatly impacted the results, and operation was more stable with rigid mounting. The piston amplitude and piston-displacer phase angle only shifted to some secondary operating mode under the test condition where the operating frequency was $95 \mathrm{~Hz}$ and the piston amplitude was $4 \mathrm{~mm}$. This makes sense considering the level of vibration from the piston at full amplitude and that the displacer amplitude achieved at $95 \mathrm{~Hz}$ matches the displacer amplitude versus frequency characterization shown in Fig. 8. The phase angle between the piston and displacer also fell into the expected range with the displacer leading the piston by 50-80 degrees at frequencies of $95-99 \mathrm{~Hz}$. Cooling of the hot-end was observed, which indicates that thermodynamics of the system are working properly. However, the motor power require to drive the cooler was on the order $3.5 \mathrm{~W}$, which is high for a $1 \mathrm{~W}$ convertor. This was most likely because of the large difference of $\sim 8 \mathrm{~Hz}$ in piston and displacer resonances.

Next steps for convertor testing will be to adjust the moving mass of the piston and displacer to bring their resonant frequencies closer together, and then repeat the characterization testing. Results of the test will be input into the analytical Sage model for comparison to empirical results. Assuming good results, the next step will be to apply heat to see if it will operate as an engine. There are two controllers available for engine testing. The first controller is an active controller consisting AC source with a $10 \mathrm{ohm}$ load in parallel to the alternator to sink power produced by the convertor, and a $2700 \mu \mathrm{F}$ tuning capacitor in series to the alternator. This type of controller give direct control of the operating frequency and piston amplitude. The second controller is a passive controller consisting of a $2700 \mu \mathrm{F}$ tuning capacitor in series with the alternator, a diode bridge rectifier, and a DC electronic load. This type of controller passively allows the convertor to operate at whatever frequency it wants, while controlling piston amplitude via control of the voltage on the DC bus. Passive control of the frequency may be advantageous for initial operation of this low power convertor as it will enable the convertor to operate at its optimum frequency for a given load.

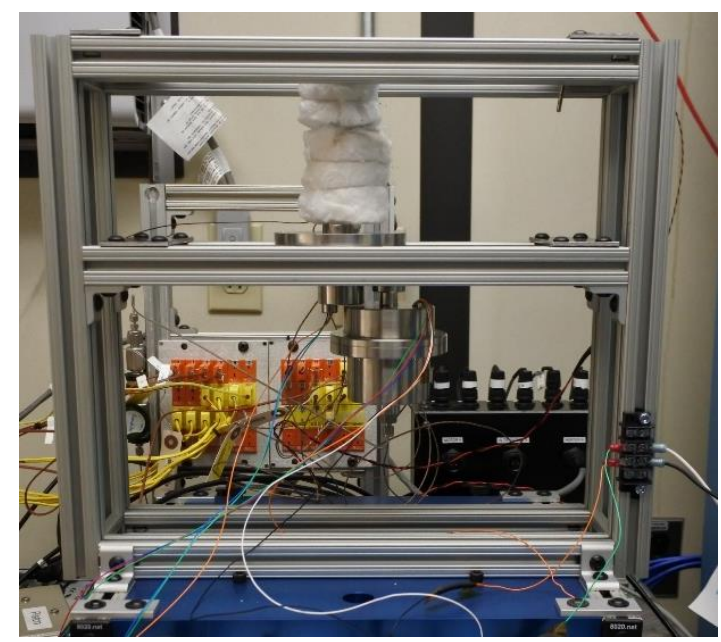

Fig. 11 Extruded aluminum rigid convertor mounting structure. 


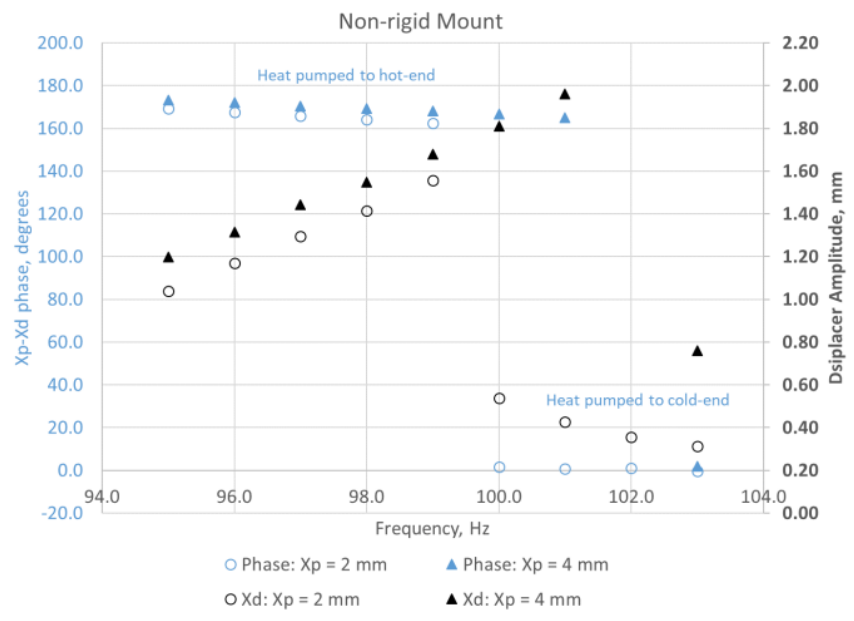

Fig. 12 Piston-Displacer phase and displacer amplitude versus frequency during testing with non-rigid mounting.

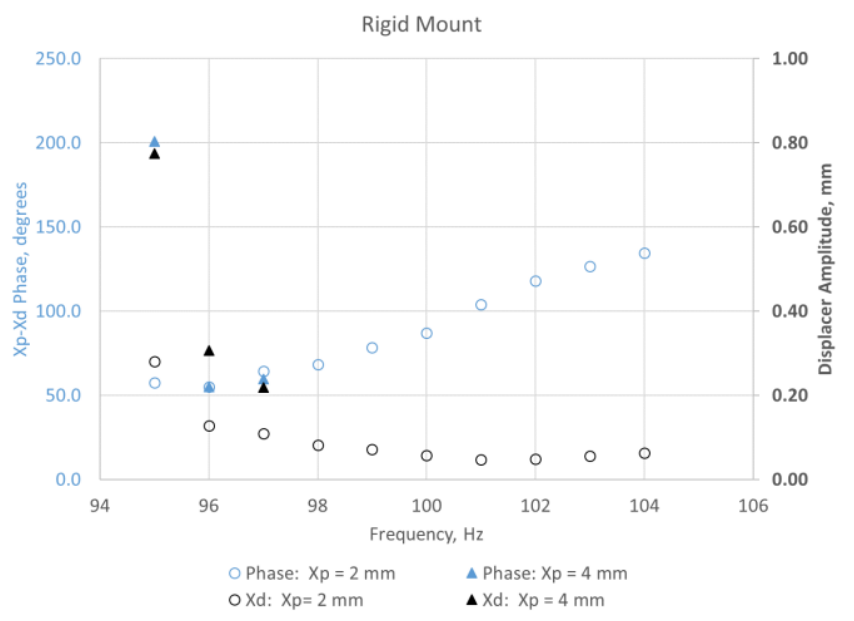

Fig. 13 Piston-Displacer phase and displacer amplitude versus frequency during testing with rigid mounting.

\section{Controller}

The free-piston Stirling convertor needs a controller that can maintain stability and rectify the power. With the desire to arrive at a simplistic controller design that can be further matured to flight, an analog controller was designed and has been tested at NASA GRC. The design is intended to control convertor dynamics and convert alternator AC voltage to DC for a spacecraft bus or energy storage system. The basic requirements are to provide load control, convert the alternating current available from the linear alternator to direct current, and shunt excess power when the energy storage is full. The analog controller was modeled in LTspice using a linearized version of the alternator. A MOSFET Hbridge architecture was used to rectify the AC voltage from the alternator to DC voltage. The load voltage control circuit contains a DC capacitor providing a DC voltage to the loads and shunts excess power not used by the battery charger or the load. The H-bridge control includes a synthetic capacitor to decrease Total Harmonic Distortion (THD) and improve efficiency. Breadboard testing was performed to validate models and enable selection of an optimal design. Representative test data in Fig. 14 and Table II shows test results of the final breadboard design. Of the methods tried, wave form smoothing was found to be the best option to successfully lower the THD and was able to achieve an AC to DC conversion efficiency of $93 \%$. A printed circuit board with the full controller design has been fabricated and is currently being assembled. The printed circuit design should improve circuit operation and resolve the noise issues causing excessive alternator current ripple on the negative portion of the sine wave shown in Fig. 14. 
Testing with the printed circuit board is anticipated for July 2019. Assuming preliminary testing of the printed circuit board controller and the 1-We convertor are successful independently, an integrated test of the controller and convertor will follow.

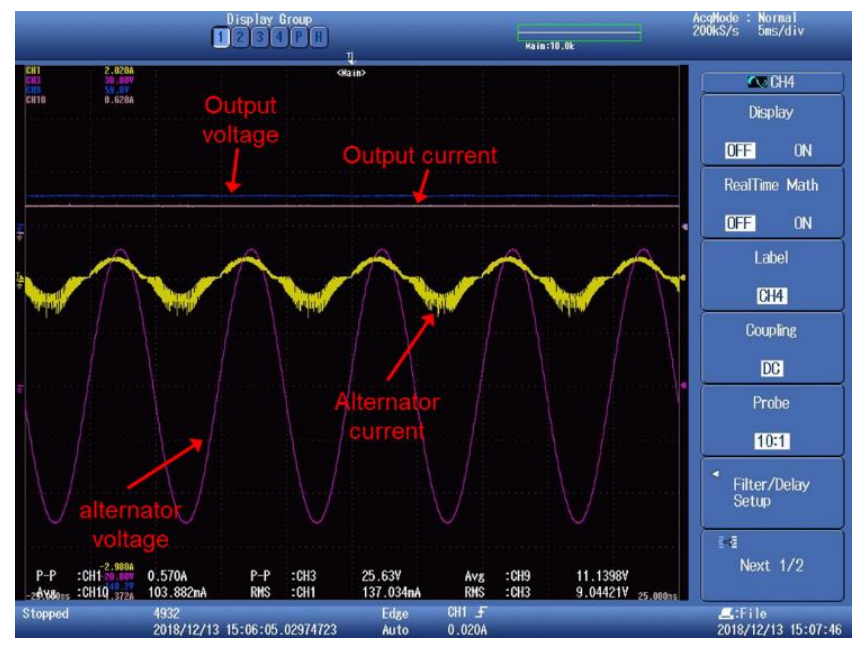

Fig. 14 Breadboard controller test data.

Table II Controller Breadboard Testing Results

\begin{tabular}{|c|c|}
\hline Alternator Voltage, $\mathrm{V}_{\mathrm{p}-\mathrm{p}}$ & 25.6 \\
\hline Alternator Power, $\mathrm{W}_{\mathrm{e}}$ & 1.24 \\
\hline Controller Voltage, $\mathrm{V}_{\mathrm{dc}}$ & 11.1 \\
\hline Controller Power, $\mathrm{W}_{\mathrm{e}}$ & 1.16 \\
\hline AC-DC Conversion Efficiency & $93 \%$ \\
\hline
\end{tabular}

\section{Conclusion}

High efficiency, low power Stirling convertors are being developed at NASA GRC for potential future smallRPS flight systems. A NASA/DOE survey identified 14 mission concepts that could use low power systems that produced 5-500 $\mathrm{mW}$ of electrical power from one or more LWRHU as a heat source. Efforts to develop the concept have focused on the maturation of an evacuated metal foil insulation package, a 1-We convertor, and a controller. Proof-of-concept hardware for each of these components has been fabricated and is currently under test. Preliminary test data for the convertor and controller development have been presented in this paper, and are showing promising results. Test results for the insulation package can be found in another paper written for this conference. This power system could be matured to extend the capability of small science payloads and instruments to enable small probes, landers, rovers, and distributed communication repeaters needed on future space exploration missions.

\section{Acknowledgments}

This work is funded through the NASA Science Mission Directorate and the Radioisotope Power Systems Program Office. The authors wish to acknowledge Barry Penswick, Steve Geng, and Roy Tew for their contributions to the Mini Stirling development effort. Any opinions, findings, conclusions, or recommendations expressed in this article are those of the authors and do not necessarily reflect the views of NASA.

\section{References}

[1] NASA Office of Space Science, "Enabling Exploration with Small Radioisotope Power Systems", JPL Pub 0410, September 2004.

[2] Wilson, S.D., Geng, S.M., Penswick, L.B., Schmitz, P.C., "Radioisotope Heater Unit-Based Stirling Power Convertor Development at NASA Glenn Research Center", NASA/TM-2018-219704. 